Article

\title{
Investigation on Hybrid Energy Storage Systems and Their Application in Green Energy Systems
}

\author{
Chao-Tsung $\mathrm{Ma}^{1, *}$ and Chin-Lung Hsieh ${ }^{2}$ \\ 1 Department of Electrical Engineering, National United University, Miaoli 36063, Taiwan \\ 2 Institute of Nuclear Energy Research (INER), Atomic Energy Council, Taoyuan 325207, Taiwan; \\ clhsieh@iner.gov.tw \\ * Correspondence: ctma@nuu.edu.tw
}

Received: 23 October 2020; Accepted: 11 November 2020; Published: 13 November 2020

\begin{abstract}
Power systems all over the world have been under development towards microgrids integrated with renewable energy-based distributed generation. Due to the intrinsic nature of output power fluctuations in renewable energy-based power generation, the use of proper energy storage systems and integrated real-time power and energy control schemes is an important basis of sustainable development of renewable energy-based distributed systems and microgrids. The aim of this paper is to investigate the characteristics and application features of an integrated compound energy storage system via simulation and a small-scale hardware system implementation. This paper first discusses the main components, working principles and operating modes of the proposed compound energy storage system. Then, a detailed design example composed of supercapacitors, batteries, and various controllers used in two typical application scenarios, peak demand shaving and power generation smoothing, of a grid-connected microgrid is systematically presented. Finally, an experimental setup with proper power converters and control schemes are implemented for the verification of the proposed control scheme. Both simulation and implementation results prove that the proposed scheme can effectively realize desired control objectives with the proposed coordinated control of the two energy storage devices.
\end{abstract}

Keywords: microgrid (MG); renewable energy (RE); distributed generation (DG); energy storage system (ESS); compound energy storage system (CESS)

\section{Introduction}

In recent years, with the increase of the global population and rapid economic development, human demand for energy is rapidly increasing and the global warming effects caused mostly by conventional power generation has become a major issue that countries all over the world must face together $[1,2]$. In addition, the use of conventional fossil fuels will soon yield problems, such as the rapid reduction in reserves and the unaffordable cost for the emission of greenhouse gases, which highlights the importance of developing alternative energy sources. Therefore, low-carbon energy technologies, such as nuclear energy and renewable energy (RE), have become the development goals of countries all over the world. Relatively mature RE power generation technologies include wind turbine (WT), solar photovoltaic (PV), hydropower, biomass energy, and geothermal energy generation, among which WT generation and solar PV generation are the mainstream of development. The projection in International Energy Outlook 2019 shows that, by 2050, the proportion of global RE power generation will increase to nearly $50 \%$, as shown in Figure 1, and the proportion of WT and solar PV together in RE power generation will increase to over $70 \%$, as shown in Figure 2 [2]. The advantages of RE include: (1) Inexhaustible and widely distributed; and (2) no fuel and extremely environmentally friendly. However, the grid connected with a large number of such unstable generation systems will have a 
negative impact on the supply power quality (PQ) and reliability of existing power systems. Therefore, in order to reduce the unavoidable impact caused by the fluctuation of RE generation, such generation systems are often combined with energy storage systems (ESSs), forming a hybrid generation system in which ESSs absorb the fluctuation of power generation, achieving power smoothing and optimal energy management [3].
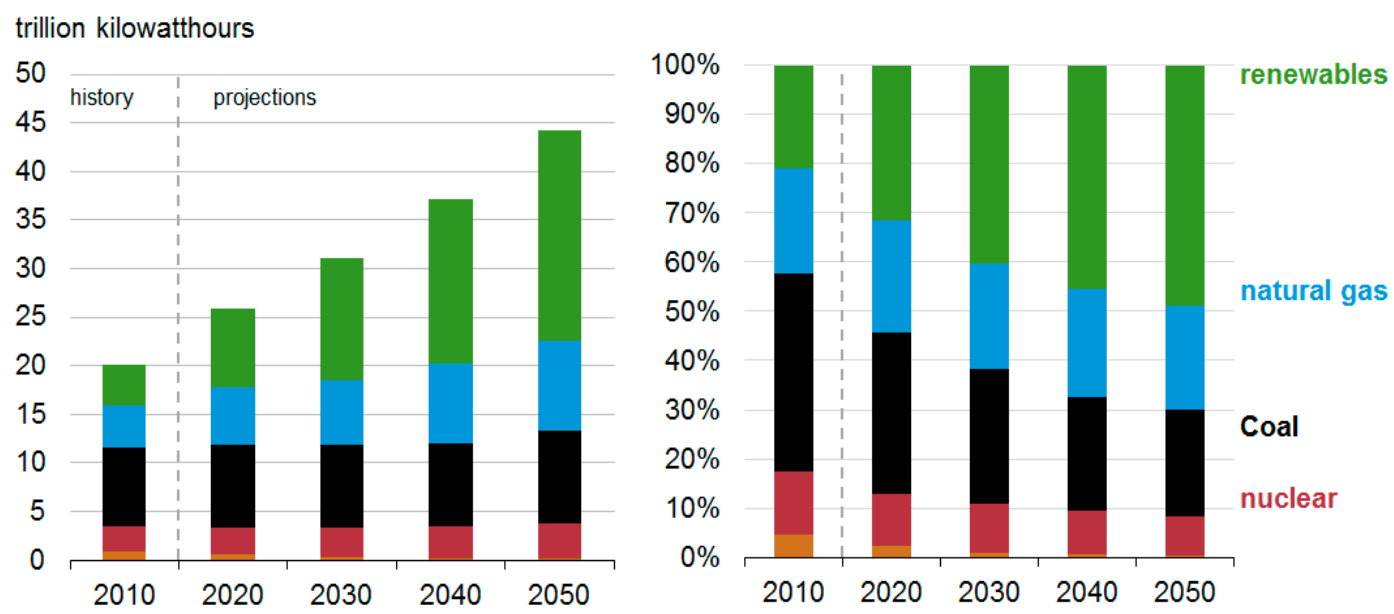

Figure 1. Record and projection of world electricity generation and shares by source [2].
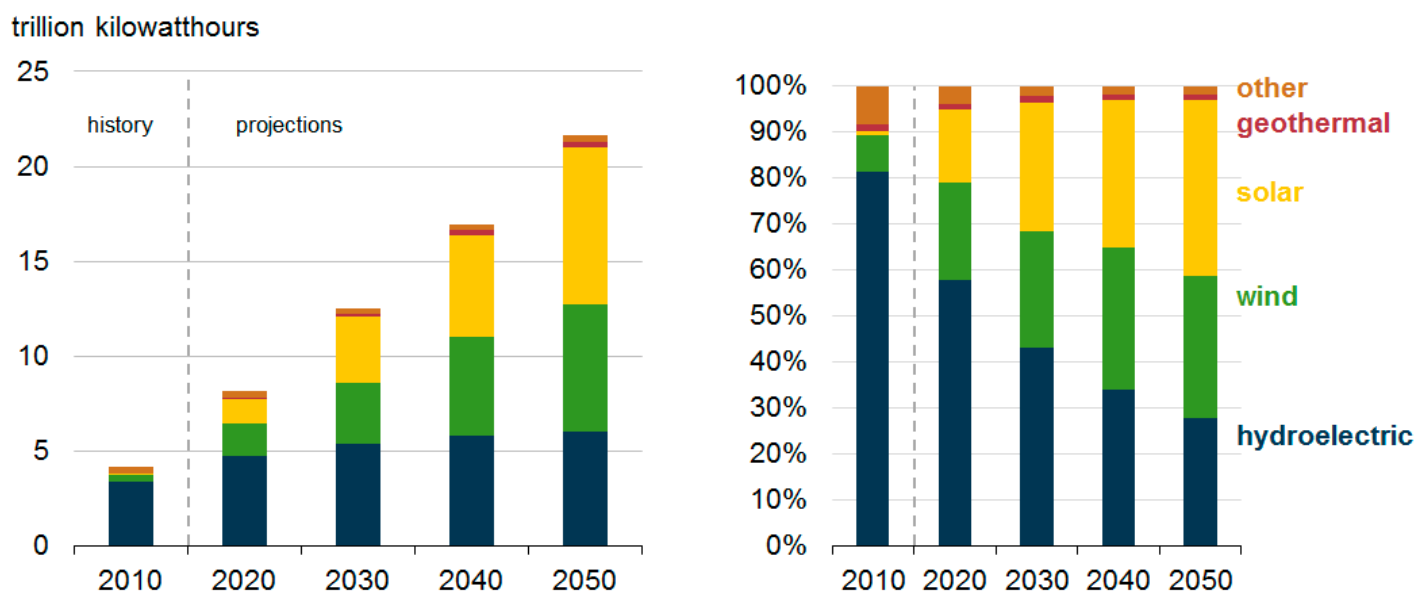

Figure 2. Record and projection of world RE electricity generation and shares by source [2].

There are two types of ESS, i.e., power-type energy storage (PTES) units, such as SC, flywheel, and superconducting magnetic energy storage, and energy-type energy storage (ETES) units, such as various types of batteries. Since these two ESSs have their own characteristics. If proper function allocation can be carried out according to certain criteria to form a compound energy storage system (CESS), the greatest overall benefit can be obtained [4]. Take the power-smoothing control in RE based power generation and energy balancing optimization control in an MG as an example, applying CESS can bring great benefits: the PTES unit can be used to smooth power fluctuations with large amplitude and high frequency in the active distribution network of the MG, which fully demonstrates its advantages of large power output density, high response speed, and considerable number of cycles; the ETES unit can be used to smooth low-frequency power fluctuation and perform real-time power balance and dispatch, which fully demonstrates its advantages of large capacity [5]. Furthermore, the abovementioned CESS can effectively reduce the number of times of charging/discharging and 
depth of discharge (DoD) of PTES to extend its life. In addition, the optimized configuration of CESS can bring more economical and reliable active distribution network operation.

At present, most of the small and medium-capacity RE power generation systems are equipped with various energy storage devices (ESD) and can be divided into standalone and grid-connected architectures. Although general hybrid RE power generation systems can be easily combined with CESSs to deal with the problem of power generation fluctuations and serve as an interface for power management, real-time power optimization and integrated management and power coordination between subsystems still pose considerable challenges. Therefore, how to design RE-based power generation systems considering both stability and high efficiency with integrated CESS topologies and control schemes has become a popular research topic. Reasonable configuration of CESS and capacity planning is a problem related to customization and system optimization. The usual method is to find the best solution through an algorithm after establishing relevant mathematical models.

In theory, there are a number of possible power interface configurations for HESS. The dualconverter configuration is considered the most flexible and robust one regarding control independency, CTES life, DC bus voltage stability and HESS utilization. This configuration is adopted as the interface topology of the proposed integrated CESS (ICESS) investigated in this paper, as shown in Figure 3.

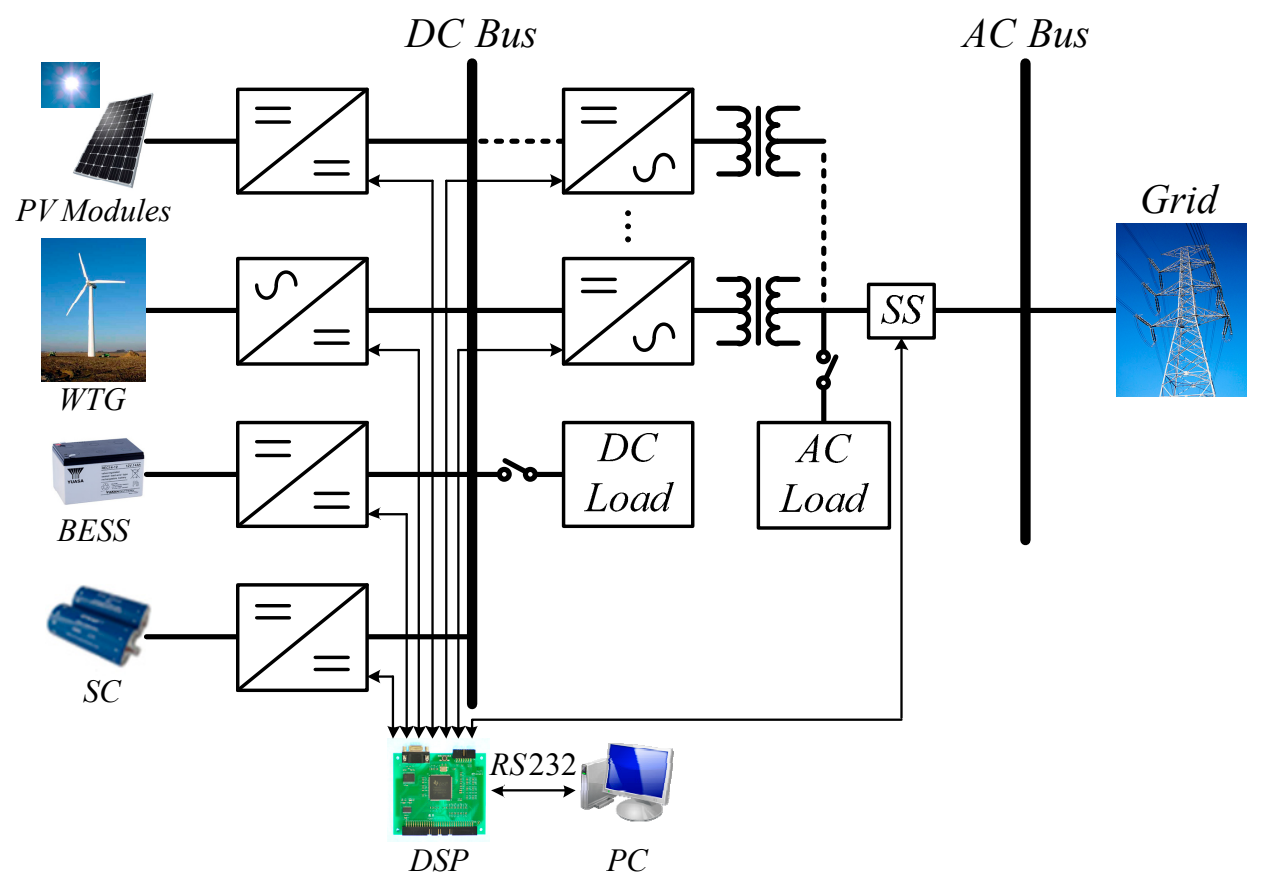

Figure 3. A dual-converter interfaced CESS and the MG system.

In the past decade, a lot of papers discussing the development and application of CESS have been published in the literature [6]. In [6], a comprehensive review on recently published papers investigating feasible topologies, usable voltage ranges, capacity utilization factors, and application cases of CESS is presented with brief comments. In the aspect of connecting the CESS with the DC bus, passive connection of both battery and supercapacitor to the system is the simplest topology [7]. It has been proved that this simple topology can effectively suppress transient load current induced by pulse load conditions with a relatively low cost; however, the system current will be drawn from or feed into the two storage units based on their respective internal impedances. This significantly limits the transient power handing capability of the supercapacitor unit. To improve the abovementioned shortcoming of passive connection and make better use of the storage units in a passive connected CESS, power electronic converters can be used to allow the real-time power flow to be actively controlled. To balance the complexity of controlling two converters and system cost, in a semi-active 
CESS topology, only one of the two ESS elements is actively controlled [8]. In a semi-active CESS topology, only one of the storage units in CESS (either battery unit [9] or supercapacitor unit [10]) is interfaced to the DC bus via a bidirectional DC/DC converter. To further improve the overall system performance and enhance the operating flexibility of the CESS a full active CESS topology was proposed [11]. In a full active CESS topology, both the power flow of battery and supercapacitor can be actively controlled via properly designed DC/DC converters. It should be noted that the performance of a full active CESS system is extremely dependent on the performance of power flow control systems designed for the DC/DC converters [12,13]. In regard to CESS applications, Hajiaghasi et al. [14] reviewed on CESSs for MG applications regarding power dispatch, RE power smoothing, PQ improvement, and ancillary service. Chen et al. [15] proposed model predictive control-based multi-time-scale optimal dispatch for a flexible traction power supply system based on a back-to-back converter, a battery-SC CESS, and PV generation. In [16], a novel adaptive fuzzy logic controller algorithm was proposed for the power management of a standalone DC MG integrated with solar PV generation and a CESS based on a battery and multiple SCs. It was pointed out that conventional fuzzy logic controllers for MG power sharing might cause over- or under-utilization of the CESS in a standalone MG because it only considered one ESD at a time. A leaderless consensus protocol was utilized in [17] for distributed cooperative control of multiple battery-SC CESSs in a DC MG with multiple PV generators. Nakka and Mishra [18] used droop and virtual inductance control for the power sharing among inverters as well as frequency regulation in an islanded hybrid AC/DC MG with PV generation and a battery-SC CESS. In [19], the fluctuation of grid-connected WT generation output was dealt with a battery-SC CESS and an adaptive SoC range control based on the concept of virtual capacity. Rain flow counting-based capacity planning and optimization of a battery-SC CESS for PV-WT generation smoothing in a complex grid-connected regional integrated power system based on wavelet packet decomposition was studied in [20]. Kumar et al. [21] studied the design, operation, and control of a vast islanded DC MG integrated with solar PV-WT generation, battery-SC CESS, step changing DC loads, and single-phase linear, nonlinear, and three-phase inductive AC loads. In [22], a nonlinear integral backstepping control was proposed for a DC MG with solar PV-WT generation and battery-SC CESS. Only local information was required for the control. Simulation results showed that the proposed control outperformed adaptive sliding mode control. A hybrid AC/DC MG with solar PV-WT generation and battery-SC CESS is controlled with a comprehensive inertial control strategy [23]. Local inertia support and cross-grid inertia support both utilized the rotational kinetic energy of the WT generators (WTGs), yielding satisfactory performance in different operating scenarios regarding load changes. Armghan et al. [24] considered the application of a battery-SC HESS for a grid-connected hybrid AC/DC MG with WT and FC generation for both grid-connected mode and islanding mode.

In the above reviewed papers, software simulation has been commonly used as the investigation method. The schematic design methods of the required controllers for the most powerful full active CESS topology using two actively controlled converters still call for investigation. This paper aims to explore how to appropriately design the required controllers and apply them to different types of ESSs in the CESS for achieving reliable and flexible control requirements. Detailed design procedure of controllers along with both simulation studies and hardware tests are carried out in this paper, in which two typical application scenarios, peak demand shaving and power generation smoothing, of a CESS in a grid-connected microgrid are presented. The complete MG system architecture used includes WT and solar PV power generation units, CESS unit, grid-tie inverter, AC and DC loads, and grid as shown in Figure 3. In the following sections of this paper, the ICESS functions and typical application modes are firstly described in Section 2 . The third section presents the controller design of the required power converters. The performance of the designed control system is verified using simulation analyses and hardware implementation tests respectively presented in Sections 4 and 5 . Finally, this paper is concluded in Section 6. 


\section{Functional Planning and Hardware Design of ICESS}

\subsection{Functional Arrangement}

In this paper, a small-scale grid-connected MG including WT and solar PV power generation systems is used as an example for the analysis and demonstration of two advanced ICESS operation modes (Mode 1 and Mode 2). In the following subsections, the two operating modes and the related control schemes used for the real-time energy management of MG will be briefly described.

\subsubsection{Operation Mode 1: Peak Demand Shaving}

The power demand of general loads varies between peaks and valleys depending on conditions such as day and night and seasons. Therefore, power companies tend to set timely power rates based on different power supply costs, which is called the time price. In terms of user benefits, shifting the electricity consumption during peak hours to off-peak hours according to the time price can greatly save electricity costs; from the perspective of power companies, peak demands can be decreased, reducing the demand in constructing new power plants and supply costs. However, even if the electricity consumption habits can be adjusted, users cannot completely avoid electricity consumption during peak hours. If there are other electricity sources, the more expensive utility power during peak hours can be better avoided. The primary condition for the operation of this operating mode is that the ETES has sufficient power, and the solar PV/WT power generation conditions exist at the same time slot. In this case, the power demand of the loads can be supplied first by solar PV/WT power generation, and the excess power is used to charge the battery; when the power generation is insufficient, the battery will make up for it. In this way, users can avoid using utility power at peak hours and achieve the goal of zero peak power demand.

\subsubsection{Operation Mode 2: RE Power Generation Smoothing}

Under the change of external power generation conditions, if solar PV/WT power generation is operated in MPPT mode, the output power will inevitably change drastically. The purpose of this control function is to reduce the impact of solar PV/WT power generation on the connected grid and improve the stability and PQ of the MG, which is achieved by fast charging/discharging of the ICESS. In this case, the bidirectional DC-DC converter performs charge and discharge control according to the power smoothing command within the safety SoC range of the ICESS; the grid-tie inverter is responsible for maintaining DC bus voltage at $200 \mathrm{~V}$. In this way, the active power at both ends can be automatically and bidirectionally balanced, achieving the goal of solar PV/WT output power smoothing.

\subsection{System Architecture}

Figure 4 shows the proposed ICESS hardware system architecture discussed in this paper. The blue blocks are the ICESS units designed and demonstrated. To build an experimental system, a 96 V/14 Ah battery bank, a 117.6 V/14.28F SC bank, a 1 kVA bidirectional single-phase grid-tie inverter, and two $1-\mathrm{kW}$ bidirectional DC-DC buck-boost battery/SC charging/discharging converters are practically constructed with switching frequency of $100 \mathrm{kHz}$. The solar PV/WT generation with maximum power point tracking (MPPT) functions is emulated using a programmable DC power supply. Related system parameters and specifications are listed in Table 1. 


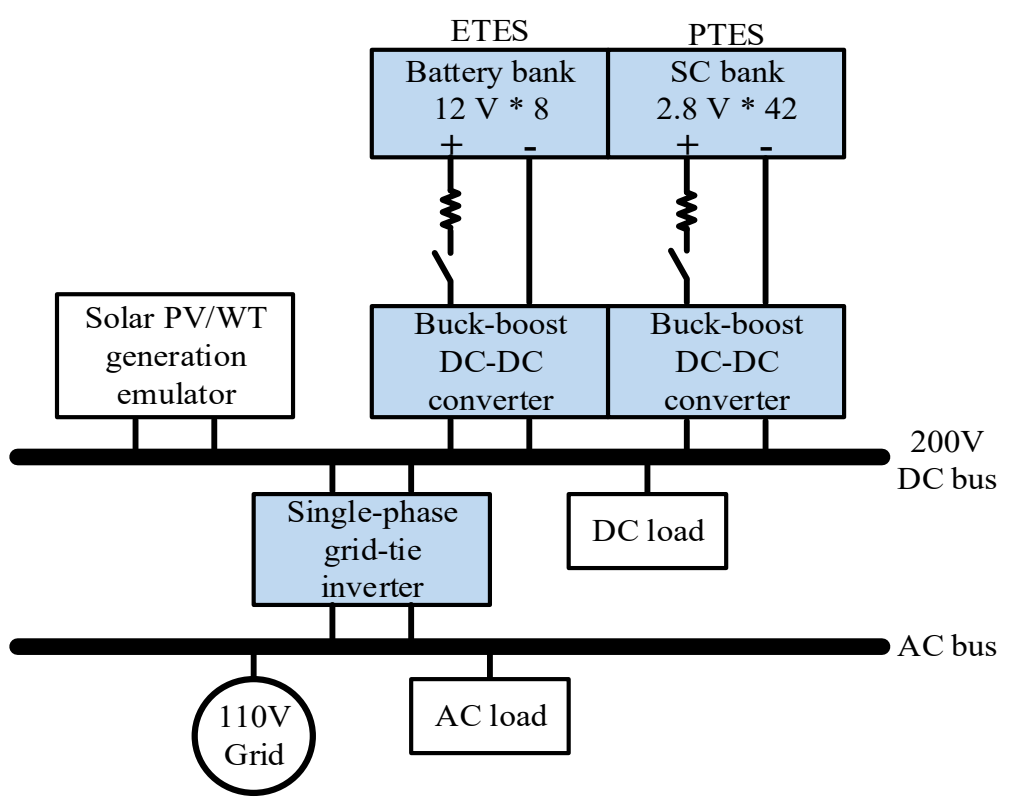

Figure 4. Proposed ICESS hardware architecture.

Table 1. Specifications of proposed ICESS and related equipment.

\begin{tabular}{cc}
\hline Item & Specification \\
\hline DC bus voltage $V_{b u s}$ & $200 \mathrm{~V}$ \\
Grid voltage $V_{s}$ & $110 \mathrm{Vrms} / 60 \mathrm{~Hz}$ \\
Maximum power output & $1 \mathrm{kVA}$ \\
Battery bank & $96 \mathrm{~V} / 14 \mathrm{Ah}$ \\
(8 batteries in series) & $(12 \mathrm{~V} / 14 \mathrm{Ah}$ each) \\
SC bank & $117.6 \mathrm{~V} / 14.28 \mathrm{~F}$ \\
(42 SCs in series) & $(2.8 \mathrm{~V} / 600 \mathrm{~F}$ each) \\
Battery charging current $I_{b}$ & Up to $10 \mathrm{~A}$ \\
PV/WTG emulator & PV: up to $600 \mathrm{~W} / 35 \sim 40 \mathrm{~V}$ \\
(Programmable DC power supply) & WTG: up to $300 \mathrm{~W}$ \\
Single-phase full-bridge & $($ with MPPT) \\
grid-tie inverter & $1 \mathrm{kVA} / 100 \mathrm{kHz}$ \\
Bidirectional DC-DC buck-boost & $(110 \mathrm{Vrms} / \mathrm{up} \mathrm{to} 10 \mathrm{Arms})$ \\
battery converter & $1 \mathrm{~kW} / 100 \mathrm{kHz}$ \\
Bidirectional DC-DC buck-boost & $1 \mathrm{~kW} / 100 \mathrm{kHz}$ \\
SC converter & Voltage regulation error $<2 \%$ \\
Inverter output voltage requirements & THD $<3 \%$ (full load, resistive) \\
Converter efficiencies & DC-DC converters: $>92 \%$ \\
\hline
\end{tabular}

\section{Controller Design of ICESS Converters}

\subsection{Single-Phase Full-Bridge Grid-Tie Inverter}

Single-phase grid-tie inverters generally adopt half-bridge or full-bridge architecture. The fullbridge architecture is adopted in this paper, as shown in Figure 5, including four power switches (Q1 Q4), an LC low-pass filter (LPF, $\mathrm{L}$, and $\left.\mathrm{C}_{\mathrm{ac}}\right)$, and a DC bus capacitor $\left(\mathrm{C}_{\mathrm{dc}}\right)$. Sinusoidal pulse width modulation (SPWM) is used to control the power switches. Dual-loop control architecture is chosen. Symbols first appearing in Figure 4 include the following: $I_{L}$ denotes inductor current; $k_{v 1}, k_{v 2}$, and $k s$ denote the sensing scales of AC voltage, DC voltage, and AC current, respectively; $v_{b u s}$ and $v_{\text {bus }}{ }^{*}$ denote the feedback and command signals of DC bus voltage, respectively; $i_{L}$ and $i_{L}{ }^{*}$ denote the 
feedback and command signals of inductor current, respectively; vsin $(\omega t)$ denotes the synchronization signal provided by the phase lock loop (PLL) using grid voltage; $v_{c o n}$ and $-v_{c o n}$ denote SPWM control signals; $\mathrm{R}_{\mathrm{L}}$ denotes $\mathrm{DC}$ equivalent load. Detailed specifications of this circuit including scaling factors for current and voltage sensors, the carrier amplitude set for SPWM and device values of output filters are listed in Table 2.

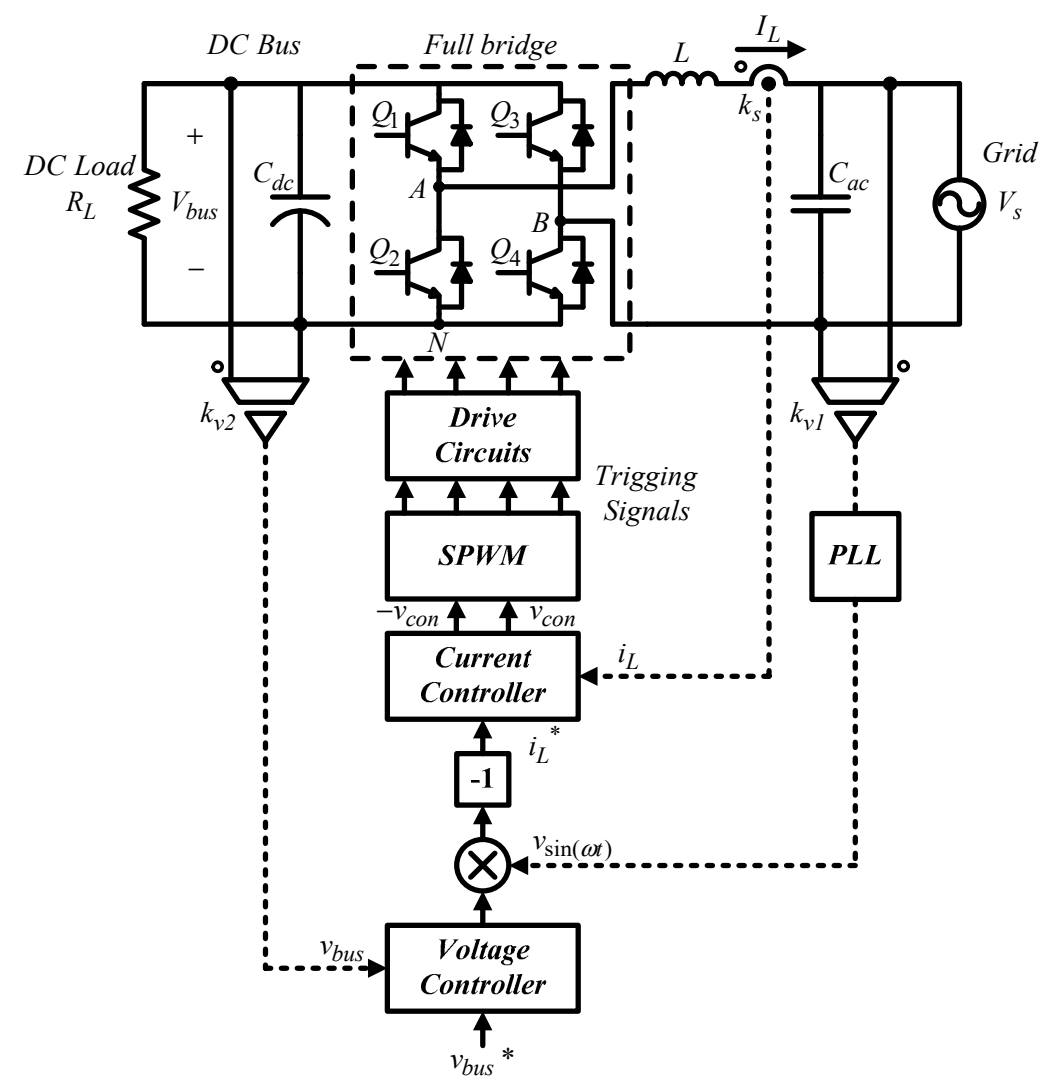

Figure 5. Control architecture of single-phase full-bridge grid-tie inverter.

Table 2. Specifications of single-phase grid-tie inverter.

\begin{tabular}{cc}
\hline Item & Value \\
\hline Carrier amplitude $v_{t}$ & $5 \mathrm{~V}$ \\
AC voltage sensing scale $k_{v 1}$ & $0.0062 \mathrm{~V} / \mathrm{V}$ \\
DC voltage sensing scale $k_{v 2}$ & $0.012 \mathrm{~V} / \mathrm{V}$ \\
AC current sensing scale $k_{s}$ & $0.05 \mathrm{~V} / \mathrm{A}$ \\
DC bus voltage variation limit & $5 \%$ \\
DC bus capacitor $C_{d c}$ & $663 \mu \mathrm{F} / 300 \sim 400 \mathrm{~V}$ \\
Filter capacitor $C_{a c}$ & $10 \mu \mathrm{F} / 165 \sim 220 \mathrm{Vrms}$ \\
Filter inductor $L$ & $97 \mu \mathrm{H}$ \\
\hline
\end{tabular}

\subsubsection{Inductor Current Controller}

In Figure 5, both switching legs are controlled using PWM technique. Letting $k_{p w m}=V_{b u s} / v_{t}$, we can express the voltage across the inductor as follows:

$$
L \frac{d I_{L}}{d t}=k_{p w m} v_{c o n}-V_{s}
$$


According to Equation (1), the grid-tie inverter inductor current control loop can be drawn, as shown in Figure 6, where $e$ denotes control error, $v_{f b}$ denotes feedback control signal, $v_{f f}$ denotes grid voltage feedforward control signal, $G_{i}$ adopts a proportional $(\mathrm{P})$ controller, whose proportional gain is $k_{1}$.

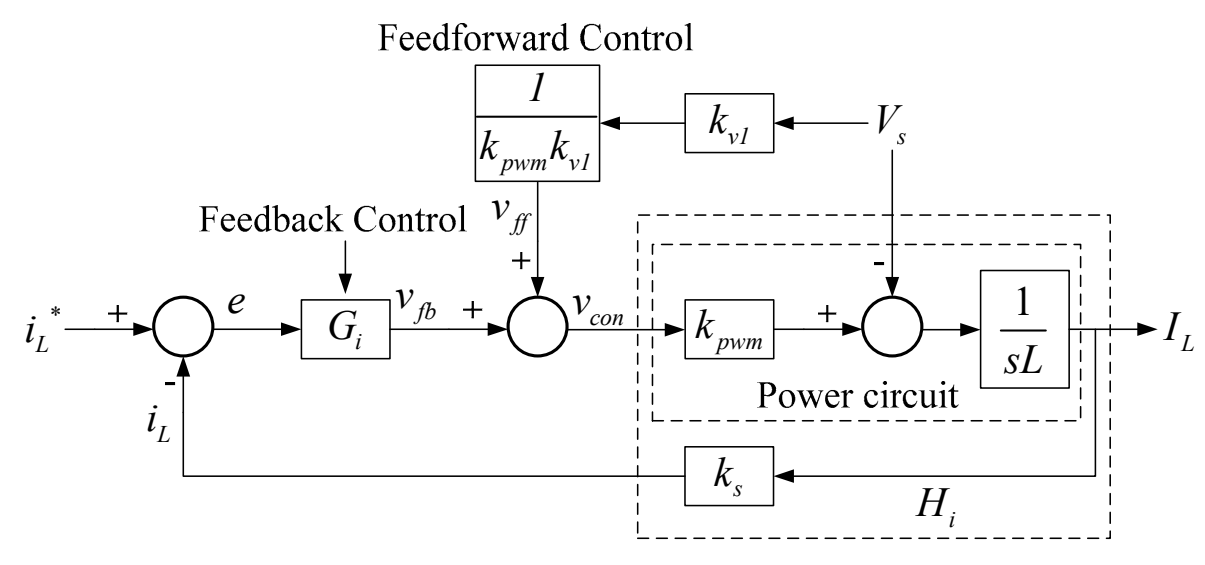

Figure 6. Grid-tie inverter inductor current control loop.

According to Figure 5, we can obtain the following:

$$
\frac{i_{L}}{i_{L}^{*}}=\frac{\frac{k_{1} k_{s} k_{p w m}}{s L}}{1+\frac{k_{1} k_{s} k_{p w m}}{s L}}=\frac{\frac{k_{1} k_{s} k_{p w m}}{L}}{s+\frac{k_{1} k_{s} k_{p w m}}{L}}=\frac{u_{i}}{s+u_{i}},
$$

where $u_{i}$ denotes the bandwidth of the inductor loop, which is designed at one fifth of the switching frequency here, and thus we can obtain the P controller:

$$
k_{1}=\frac{u_{i} \times L}{k_{s} \times k_{p w m}}=\frac{\frac{1}{5} \times 100 k \times 2 \pi \times 100 \mu}{0.05 \times 40} \cong 6.28
$$

\subsubsection{Bus Voltage Controller}

Considering the unity power factor, we can obtain the equivalent circuit of the grid-tie inverter with the AC power mapped onto the DC side, as shown in Figure 7 , where $I_{r}$ denotes load current, $I_{c}$ denotes capacitor current, $I_{b u s}$ denotes DC bus current, $v_{s}$ and $i_{s}$ denote grid voltage and current, respectively.

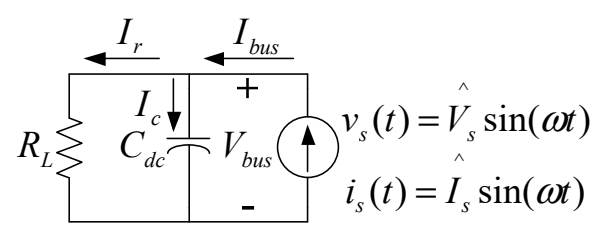

Figure 7. Equivalent circuit of grid-tie inverter with AC power mapped onto the DC side.

In Figure 6:

$$
\frac{V_{b u s}}{\hat{I_{S}}}=\frac{\frac{k_{d c}}{C_{d c}}}{s+\frac{1}{R_{L} C_{d c}}}=\frac{\frac{k_{d c}}{C_{d c}}}{s+a} .
$$

According to Equation (4), the grid-tie inverter DC bus voltage control loop can be drawn, as shown in Figure 8, where $i_{s}{ }^{*}$ denotes grid current feedback, and $G_{v}$ adopts a type II controller. Here, it is assumed that $u_{i}$ is much greater than the voltage loop bandwidth $\left(u_{v}\right)$. 


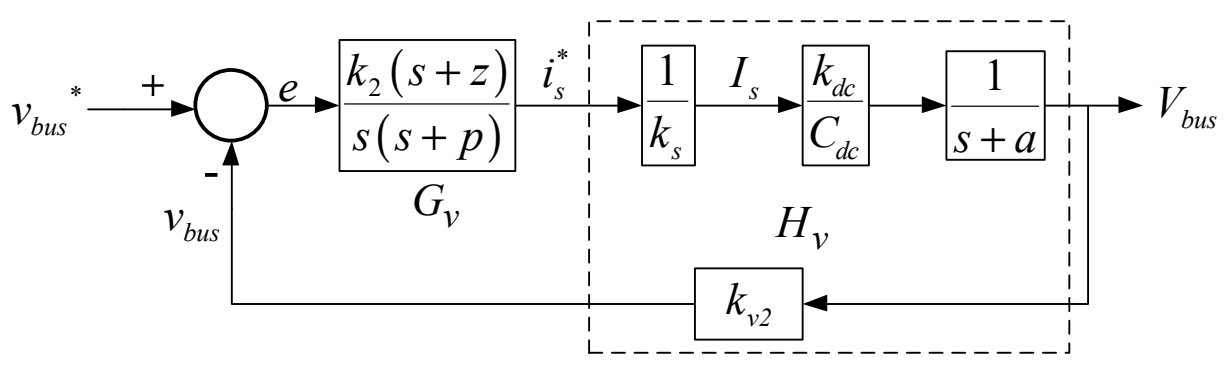

Figure 8. Grid-tie inverter DC bus voltage control loop.

In Figure 7, the transfer function of the plant can be expressed as follows:

$$
H_{v}(s)=\frac{k_{v 2} k_{d c}}{k_{s} C_{d c}(s+a)}
$$

Considering the influence of the secondary ripple of the DC bus voltage on the stability of the controller, the gain crossover frequency of the voltage control loop is set to $16 \mathrm{~Hz}$, and the pole and zero of the controller are set at $180 \mathrm{rad} / \mathrm{s}$ and $30 \mathrm{rad} / \mathrm{s}$, respectively, yielding the transfer function of the type II controller:

$$
G_{v}(s)=\frac{k_{2}(s+z)}{s(s+p)}=\frac{154 \cdot 1(s+30)}{s(s+180)} .
$$

Figure 9 shows the open-loop Bode plot of the DC bus voltage control loop. The phase margin is $65^{\circ}$.

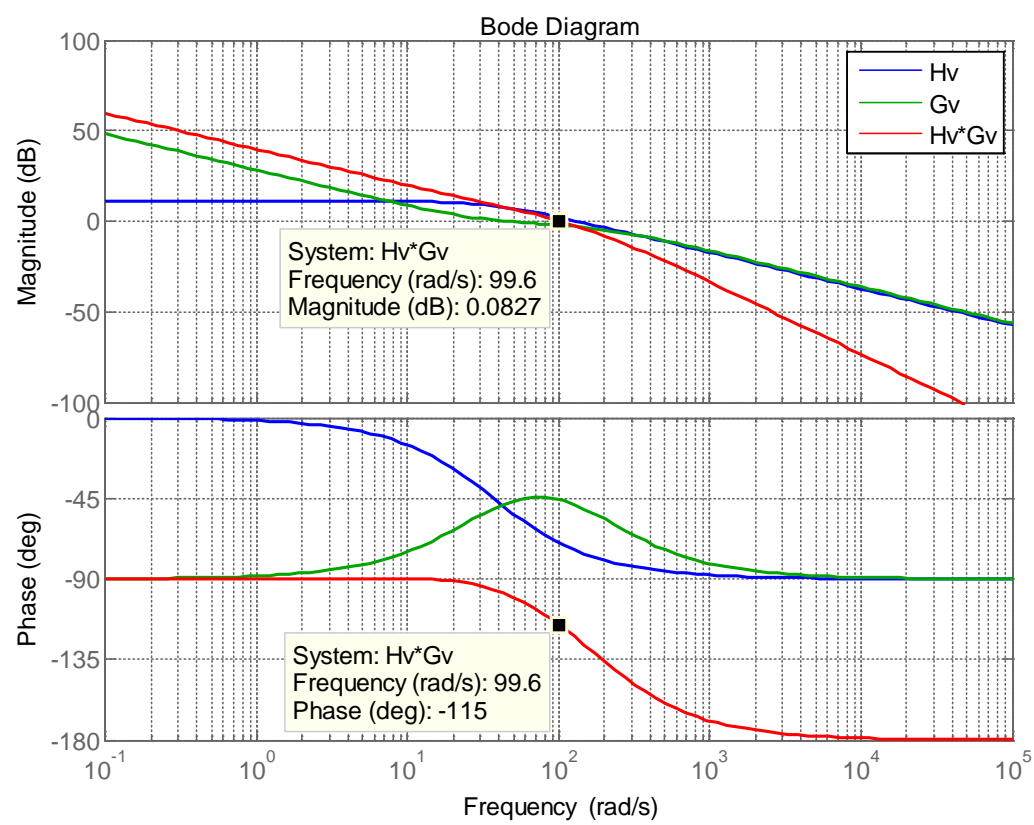

Figure 9. Open-loop Bode plot of grid-tie inverter DC bus voltage control loop.

\subsection{DC-DC Buck-Boost Converter}

The control interfaces for real-time bidirectional charging/discharging required by the battery and SC banks are identical, adopting the configuration of two-switch buck-boost converter, as shown in Figure 10, including two power switches $\left(\mathrm{Q}_{1}, \mathrm{Q}_{2}\right)$, a low-voltage $\mathrm{LC}$ filter $\left(L\right.$ and $\left.C_{L V}\right)$ and a high-voltage capacitor $\left(C_{H V}\right)$. This converter uses single-loop control architecture to control the inductor current. In Figure 10, the symbols appearing for the first time are as follows: $V_{b}$ denotes ESD voltage, $I_{b}$ denotes ESD current (equals to inductor current of the converter), $i_{b}$ and $i_{b}{ }^{*}$ denote feedback and command 
signals of ESD current, respectively. The control command can be determined according to the SoC of the ESDs and system operation strategy for real-time control. Detailed system specifications including the maximum and minimum duty cycles respectively set for the boost and buck operating modes of ICESS converters, output current ripple limitation and filter parameters are listed in Table 3.

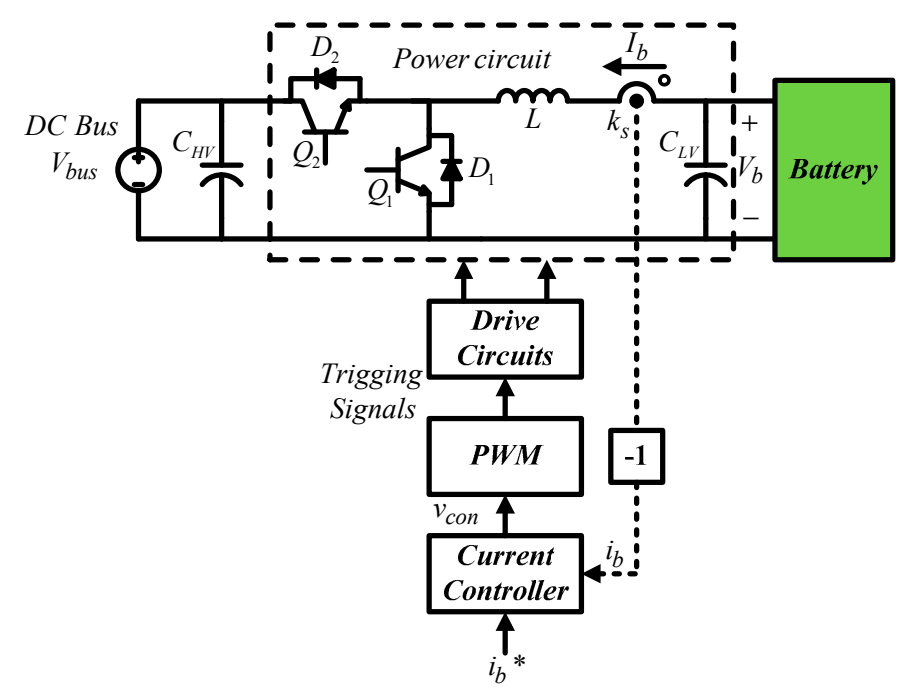

Figure 10. Control architecture of buck-boost battery/SC converter.

Table 3. Specifications of buck-boost battery/SC converter.

\begin{tabular}{cc}
\hline Item & Value \\
\hline Maximum duty cycle, $D$ (boost mode) & 0.85 \\
Minimum duty cycle, $D$ (buck mode) & 0.15 \\
Current output current ripple limitation & $10 \%$ \\
High-voltage capacitor $C_{H V}$ & $463 \mu \mathrm{F} / 300 \sim 400 \mathrm{~V}$ \\
Low-voltage capacitor $C_{L V}$ & $8.63 \mu \mathrm{F} / 250 \mathrm{Vrms}$ \\
Filter inductor $L$ & $200 \mu \mathrm{H}$ \\
\hline
\end{tabular}

When operating in buck mode, the small-signal model of the buck-boost converter including the perturbance (the symbols with hats) can be expressed as follows:

$$
s L \hat{i_{b}}(s)=D v_{b u s}^{\wedge}(s)+V_{b u s} \hat{d}(s)-\hat{v_{b}}(s)
$$

According to Equation (7), the small signal model can be visualized, as shown in Figure 11:

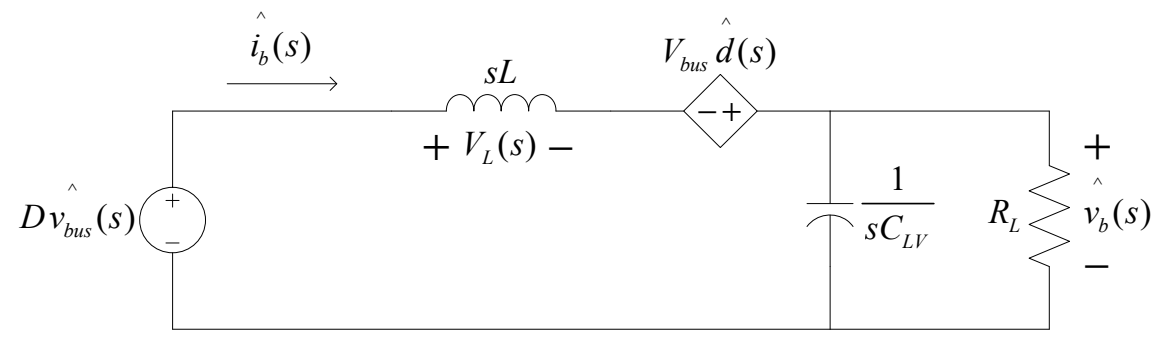

Figure 11. Small-signal model of battery/SC converter inductor current. 
Assuming that there is no perturbance on the DC bus, we can obtain the following:

$$
\frac{\hat{i_{b}}(s)}{\hat{d}(s)}=\frac{V_{b u s}}{\left[s L+\frac{R_{L}}{1+s C_{L V} R_{L}}\right]}=\frac{V_{b u s}\left(1+s C_{L V} R_{L}\right)}{s L\left(1+s C_{L V} R_{L}\right)+R_{L}}=\frac{V_{b u s}}{L} \cdot \frac{s+\frac{1}{R_{L} C_{L V}}}{s^{2}+\frac{1}{R_{L} C_{L V}} s+\frac{1}{L C_{L V}}} .
$$

The inductor current control loop drawn according to Equation (8) is shown in Figure 12, where type II controller is adopted, and K-factor is used for quantification design.

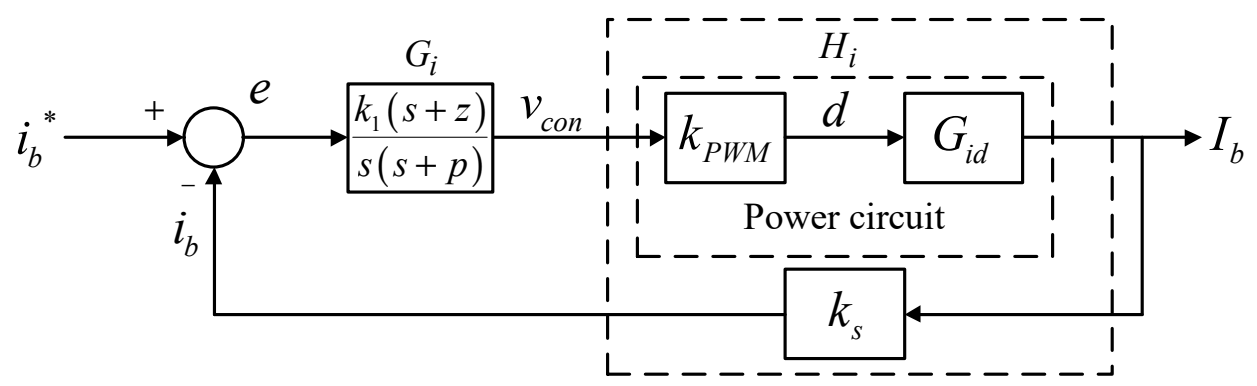

Figure 12. Battery/SC converter inductor current control loop.

In Figure 12, the transfer function of the plant can be expressed as follows:

$$
\begin{gathered}
H_{i}(s) \quad k_{P W M} \cdot G_{i d} \cdot k_{s}=\frac{1}{v_{t}} \times \frac{\hat{i_{b}}(s)}{\hat{d}(s)} \times k_{s} \\
=\frac{k_{s} \cdot V_{b u s}}{v_{t} \cdot L} \cdot \frac{s+\frac{1}{R_{L} C_{L V}}}{s^{2}+\frac{1}{R_{L} C_{L V}} s+\frac{1}{L C_{L V}}}=\frac{10000 s+1.302 \times 10^{8}}{s^{2}+1.302 \times 10^{4} s+5 \times 10^{8}}
\end{gathered}
$$

The crossover frequency is set at one tenth of the switching frequency, which is roughly 62,832 $\mathrm{rad} / \mathrm{s}$, and thus the gain and phase at crossover frequency can be obtained:

$$
\begin{aligned}
H_{i}\left(\omega_{c i}\right) & =\text { Gain }_{H_{i}} \angle A n g l l_{H_{i}} \\
& =0.1811 \angle-88.36^{\circ}
\end{aligned}
$$

The required phase boost at crossover frequency is as follows:

$$
\begin{aligned}
\text { Phase Boost } & =\text { Phase Margin }- \text { Angle }_{H_{i}}-90^{\circ} \\
& =60^{\circ}-(-88.36)-90^{\circ}=58.36^{\circ}
\end{aligned}
$$

yielding the $K$-factor:

$$
K_{\text {factor }}=\tan \left(\frac{\text { Phase Boost }}{2}+45^{\circ}\right)=\tan \left(\frac{58.36^{\circ}}{2}+45^{\circ}\right)=3.5291 .
$$

Thus, we can obtain the zero and pole of the type II controller:

$$
\begin{gathered}
z=\frac{\omega_{c i}}{K_{\text {factor }}}=\frac{62,832}{3.5291} \cong 17,804 \mathrm{rad} / \mathrm{s} ; \\
p=\omega_{c i} \cdot K_{\text {factor }}=62,832 \times 3.5291 \cong 221,740 \mathrm{rad} / \mathrm{s} .
\end{gathered}
$$

Required gain compensation at crossover frequency is as follows:

$$
k_{1}=\frac{p}{\text { Gain }_{H_{i}}}=\frac{221,740}{0.1811}=1.2244 \times 10^{6} .
$$


As a result, the transfer function of the designed controller can be obtained:

$$
G_{i}(s)=\frac{k_{1}(s+z)}{s(s+p)}=\frac{1.2244 \times 10^{6}(s+17,804)}{s(s+221,740)} .
$$

Figure 13 shows the open-loop Bode plot of the inductor current control loop. As can be seen in Figure 13 , the phase margin is $60^{\circ}$.

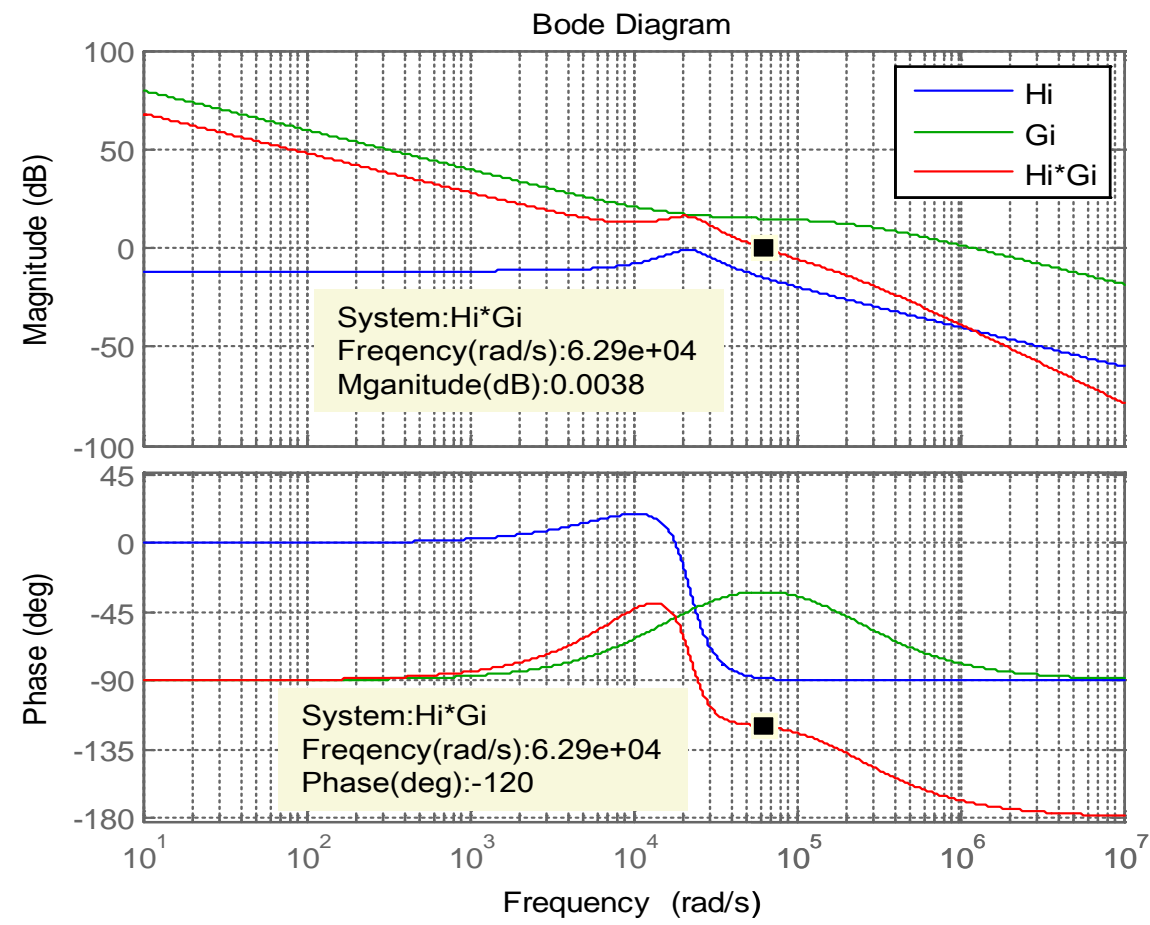

Figure 13. Open-loop Bode plot of battery/SC converter inductor current control loop.

\section{Case Simulation}

This section investigates the performance of the proposed ICESS in implementing various advanced system-wide functional operations and power charging/discharging control through the planning and simulation of application cases based on grid-connected solar PV/WT generation systems and the power control of MG.

\subsection{Case 1: Peak Demand Shaving (Operation Mode 1)}

In this mode, the DC load power demand is set to $300 \mathrm{~W}$. The system calculates the charging/discharging command of the battery in real time according to solar PV and WT generation to achieve peak demand shaving requirements. The goal of this case is to realize the ideal zero power demand from the grid, that is, no electricity from the grid is used during peak hours. Figure 14 shows related power variation scenarios.

Figures 15 and 16 show the simulation results without and with peak power shaving function, respectively. It can be known from the results that, if the solar PV/WT generation is less than $300 \mathrm{~W}$, the system can discharge the ICESS battery to help supply the load demand; when solar PV/WT generates more than $300 \mathrm{~W}$, the battery can absorb the excess power, and users can completely avoid using the utility power. 

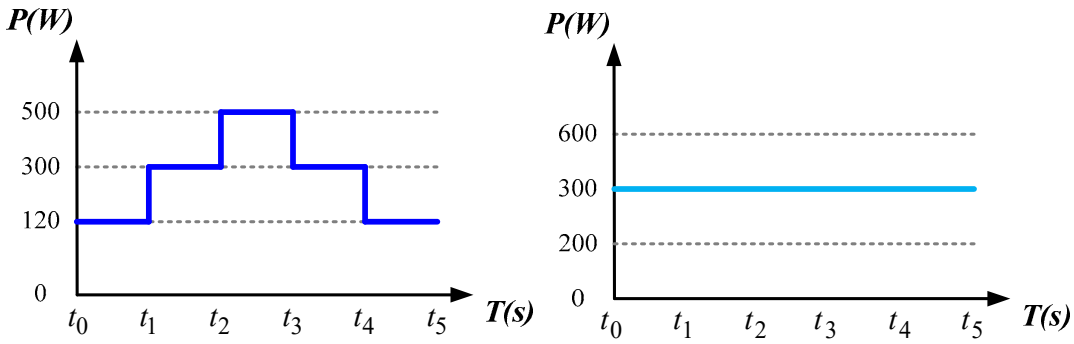

(a)

(b)
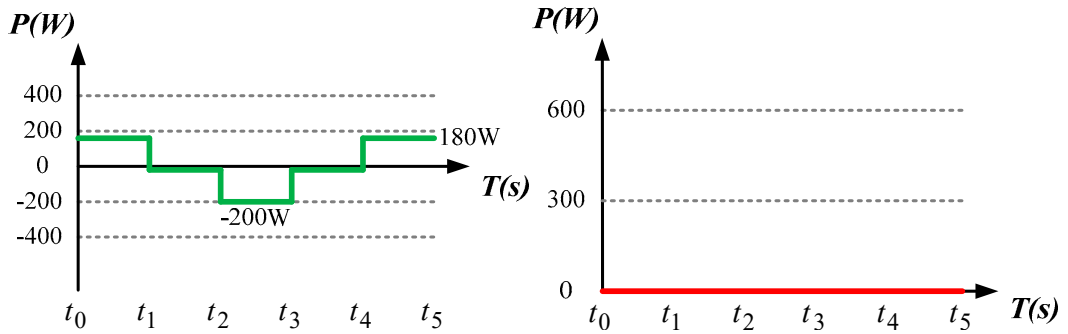

(c)

(d)

Figure 14. Power change scenarios of case 1: (a) Solar PV/WT generation; (b) load power; (c) ICESS power; (d) grid power.

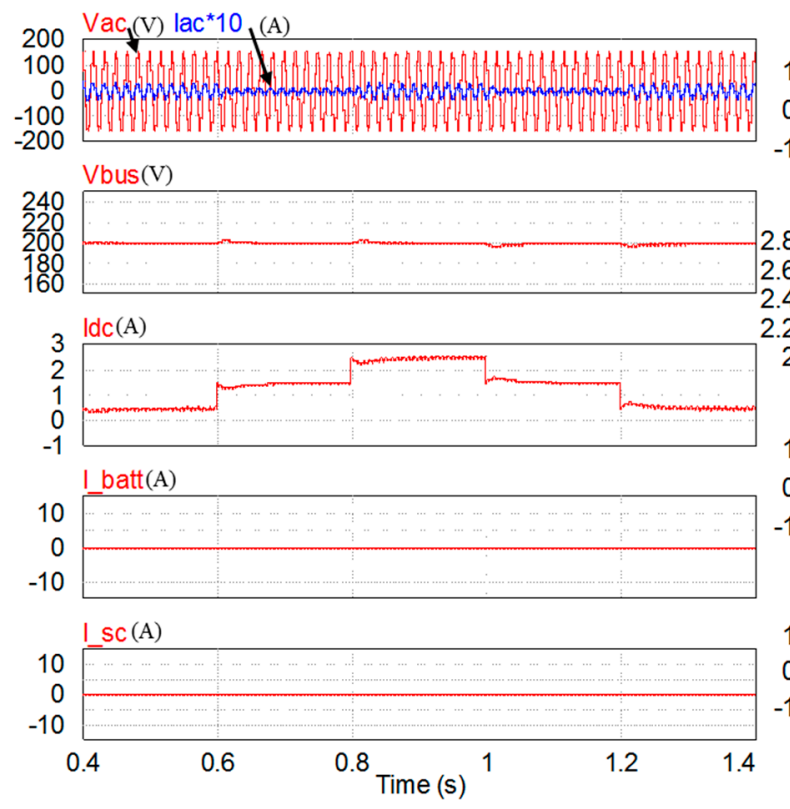

(a)
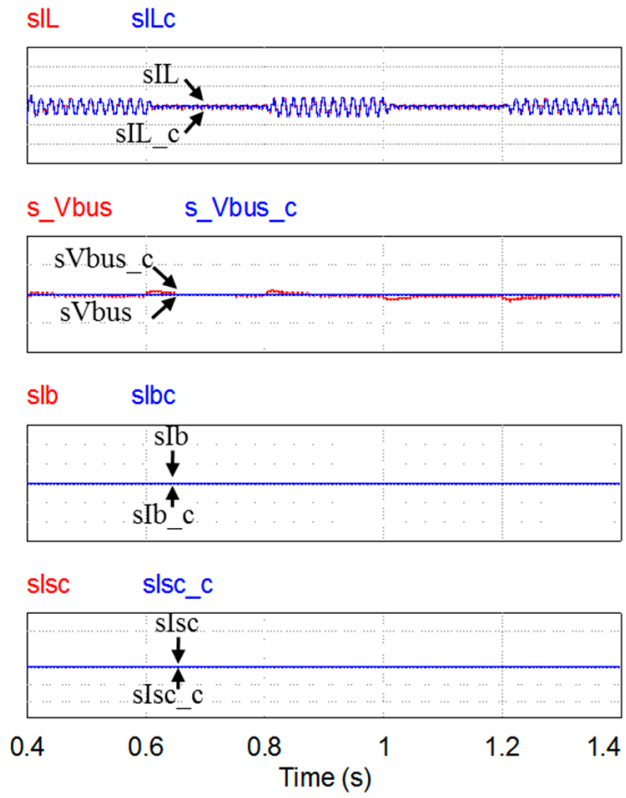

(b)

Figure 15. Simulation results without peak demand shaving: (a) Grid AC voltage and current/DC bus voltage/DC bus current/battery current/SC current; (b) feedback and command signals of grid AC current/DC bus voltage/battery current/SC current. 


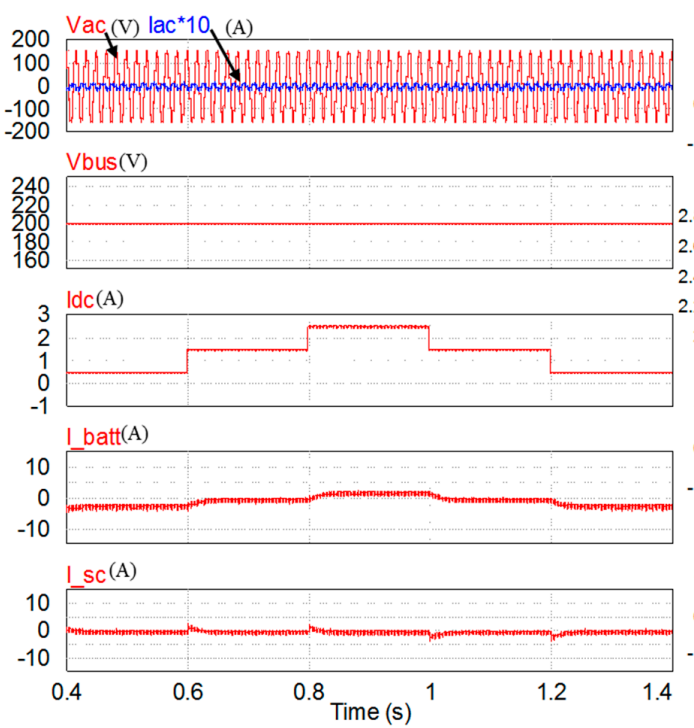

(a)
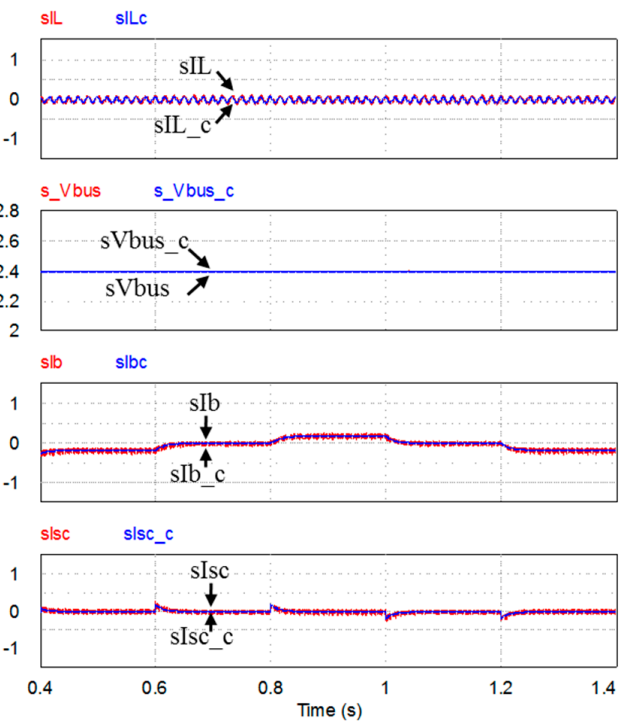

(b)

Figure 16. Simulation results with peak demand shaving: (a) Grid AC voltage and current/DC bus voltage/DC bus current/battery current/SC current; (b) feedback and command signals of grid AC current/DC bus voltage/battery current/SC current.

\subsection{Case 2: RE Power Generation Smoothing (Operation Mode 2)}

In this mode, the AC power injected to the grid is fixed at $200 \mathrm{~W}$. Figures 17 and 18 show the simulation results without and with RE generation smoothing function, respectively. From the simulation results, it can be known that if the solar PV/WT generation is less than $200 \mathrm{~W}$, the control system can instantly make up the power fed to the grid by discharging the ICESS battery; the excess power generated by solar PV/WT can be absorbed by the battery to achieve the purpose of smoothing the power fed to the grid.

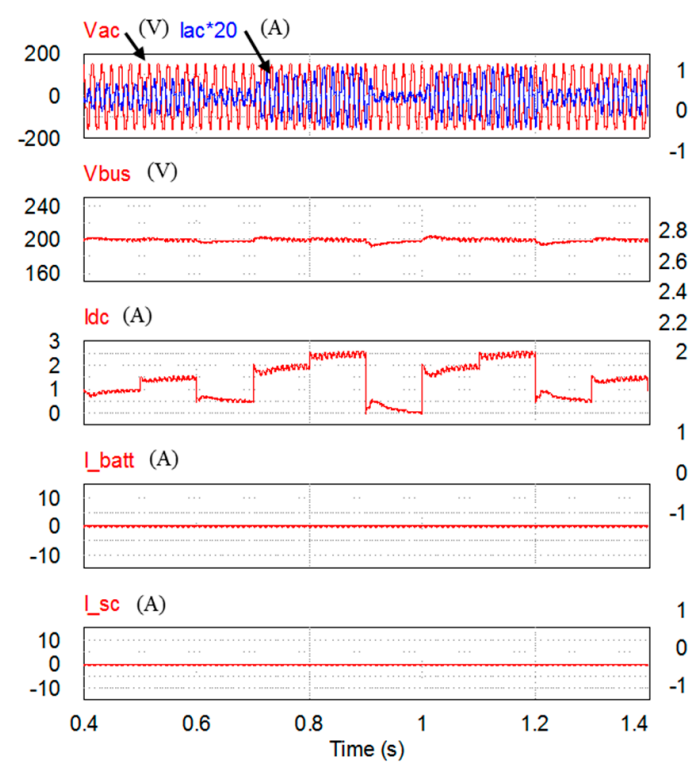

(a)

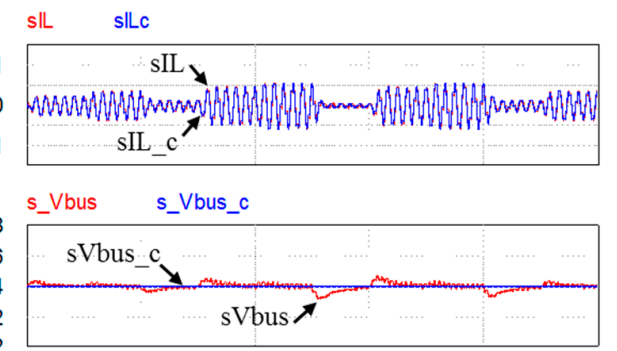

slb slbc
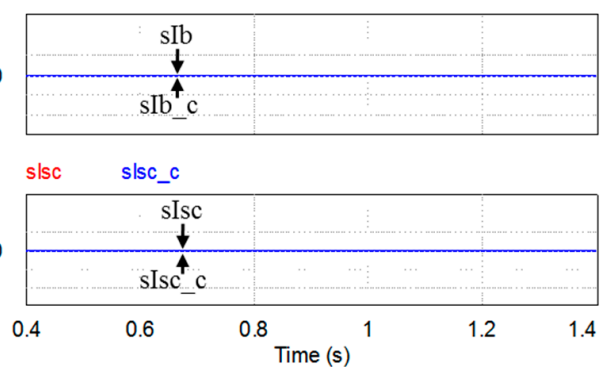

(b)

Figure 17. Simulation results without RE generation smoothing: (a) Grid AC voltage and current/DC bus voltage/DC bus current/battery current/SC current; (b) feedback and command signals of grid AC current/DC bus voltage/battery current/SC current. 


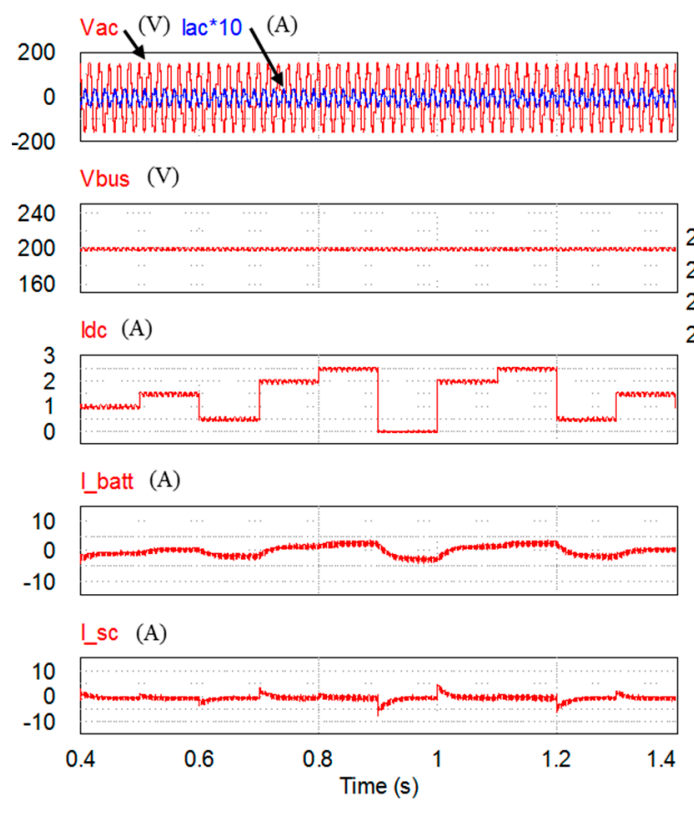

(a)

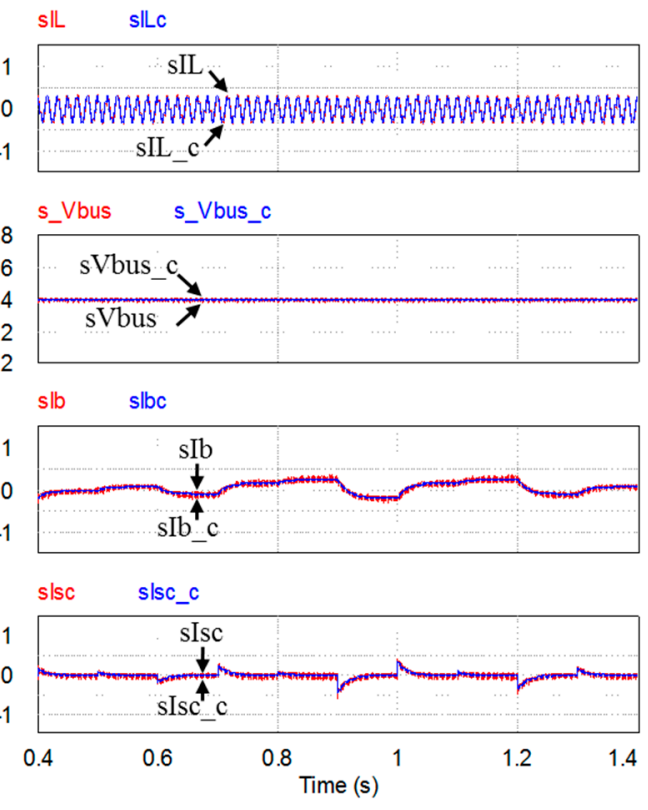

(b)

Figure 18. Simulation results with RE generation smoothing: (a) Grid AC voltage and current/DC bus voltage/DC bus current/battery current/SC current; (b) feedback and command signals of grid AC current/DC bus voltage/battery current/SC current.

\section{Hardware Implementation}

Following the simulation of two typical application scenarios of the proposed ICESS presented in the previous section, considering the hardware circuit specifications and the test conditions of current laboratory equipment, a 1kVA ICESS hardware experimental system has been developed. A Texas Instruments (TI) digital signal processor (DSP) is used to realize fully digital integration and coordinated control of power converters in ICESS. The overall performance of the ICESS system is verified by experimental test results with the same system parameters and operating conditions presented in simulation cases. Figure 19 shows a photo of the complete hardware experiment environment.

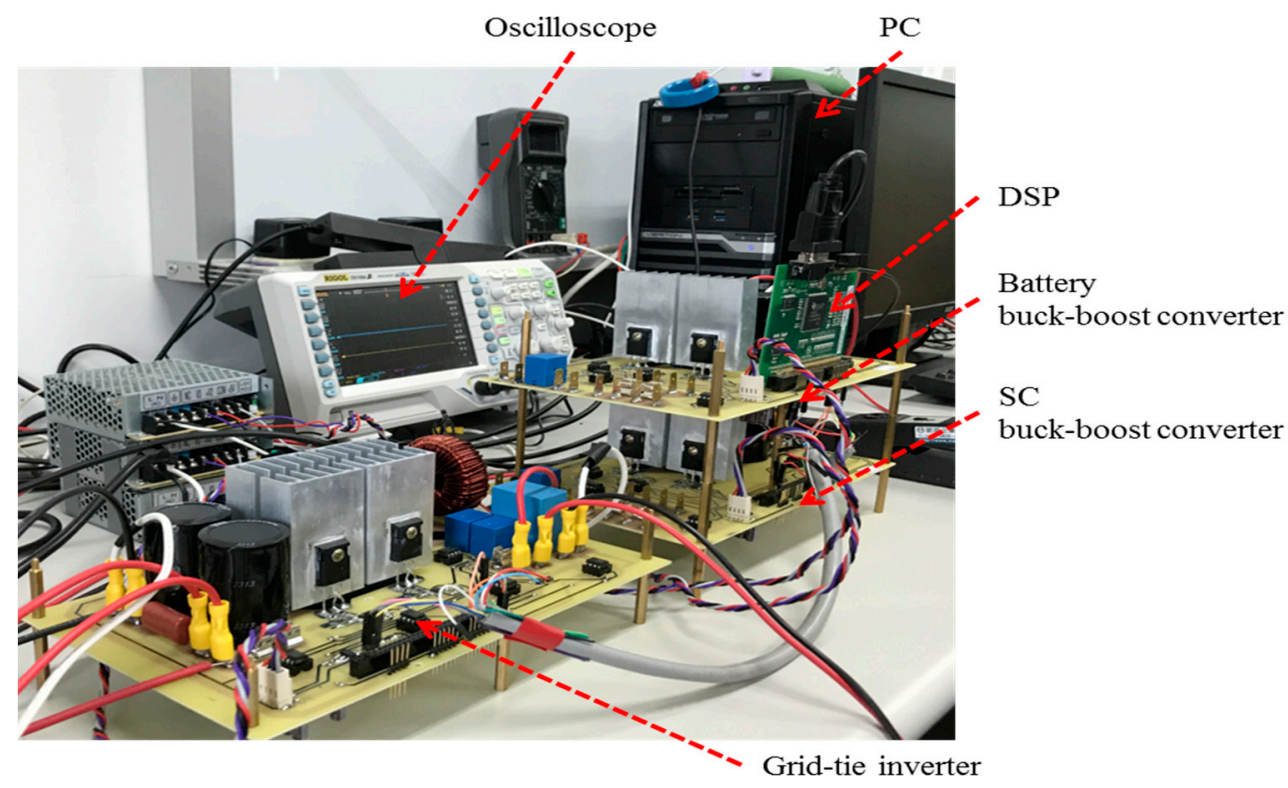

Figure 19. Photo of complete hardware setup and experiment environment. 


\subsection{Case 1: Peak Demand Shaving (Operation Mode 1)}

The condition of this case is the same as that of the simulation in Section 4.1, and the experimental results are used to analyze and compare with the simulation results. Figures 20-22 show the measuring results of the implementation. As can be seen from the measured waveforms, the same performance of peak demand shaving control as that of simulation is observed. In Figure 21, with the function of peak demand shaving being activated the control goal of this control case, realizing an ideal zero power demand (Ch2) from the grid, is perfectly achieved. As shown in Figure 22, both the output currents of the battery $(\mathrm{Ch} 3)$ and supercapacitor $(\mathrm{Ch} 4)$ banks are stably regulated as commanded.

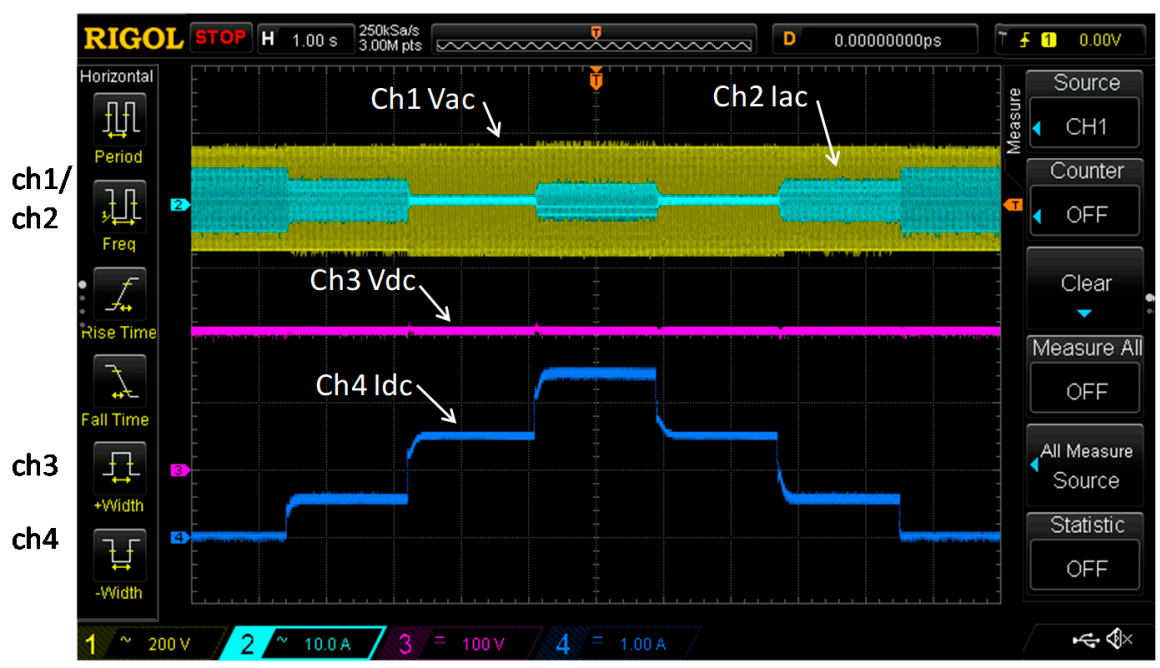

Ch1:200V/div Ch2 :10A/div Ch3:100V/div Ch4:1A/div Time:1s/div

Figure 20. Implementation results without peak demand shaving: Grid AC voltage and current/DC bus voltage/DC bus current.

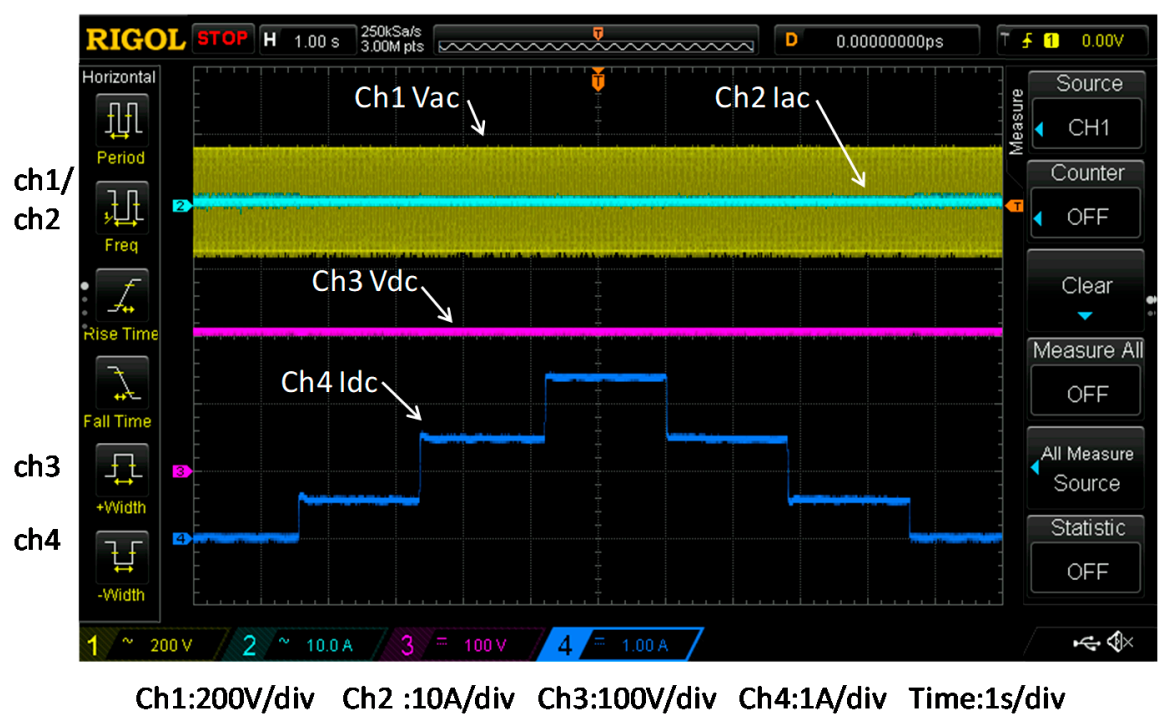

Figure 21. Implementation results with peak demand shaving: Grid AC voltage and current/DC bus voltage/DC bus current. 


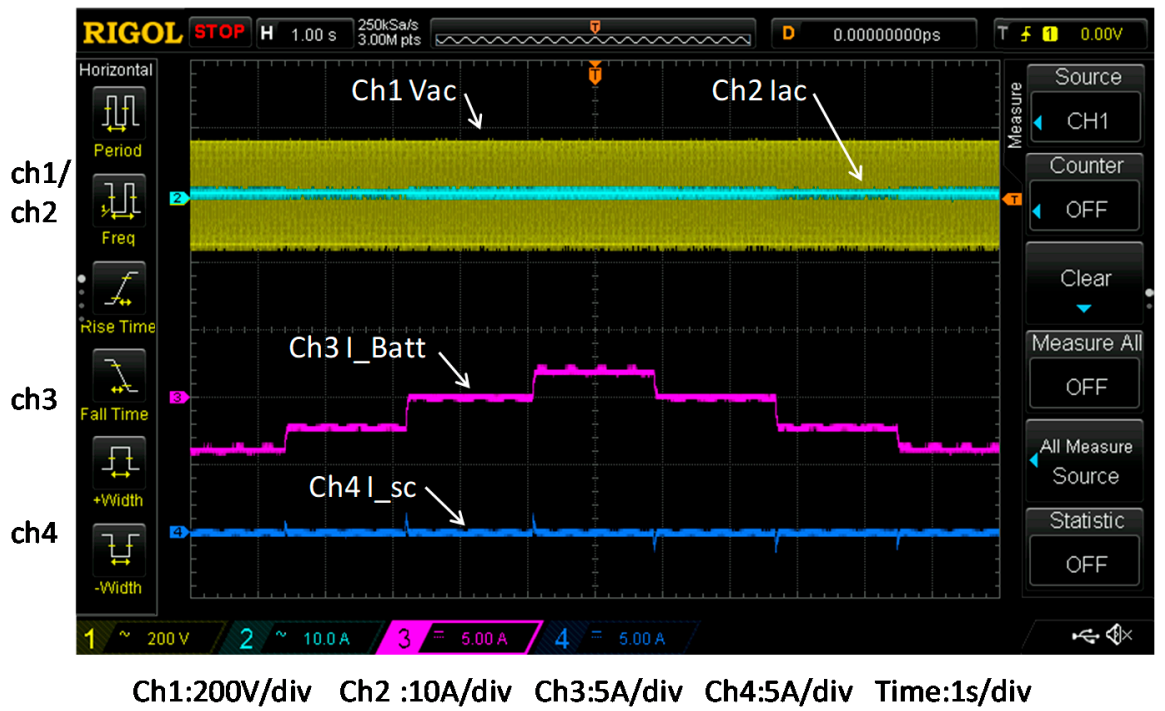

Figure 22. Implementation results with peak demand shaving: Grid AC voltage and current/battery current/SC current.

\subsection{Case 2: RE Generation Smoothing (Operation Mode 2)}

For comparison purposes, the system parameters and operating condition of this case are the same as that of the simulation case presented in Section 4.2, and the experimental results are used to check with the simulation results. Figures 23-26 shows the measured results of the implementation. As can be seen in 23-26, the same result of effective RE generation smoothing is observed. Figure 23 shows the waveforms of disturbed grid AC voltage and fluctuating current, DC bus voltage, and current injected to DC bus without smoothing control. The corresponding set of waveforms with the power smoothing control function being activated are shown in Figure 25. As can be seen in Figure 25, the waveforms of the AC voltage and current are perfectly stable and the designed real-time tracking control of the currents of the battery (Ch3) and supercapacitor (Ch4) banks in ICESS shown in Figure 26 is achieved.

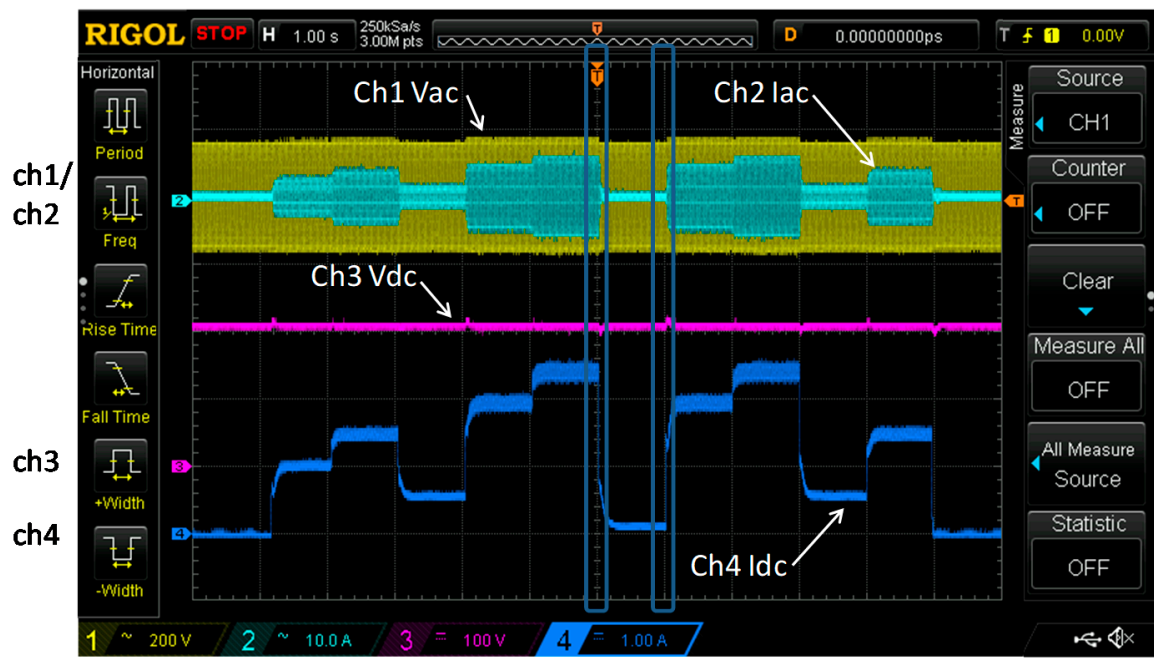

Ch1:200V/div Ch2:10A/div Ch3:100V/div Ch4:1A/div Time:1s/div

Figure 23. Implementation results without RE generation smoothing: Grid AC voltage and current/DC bus voltage/DC bus current. 


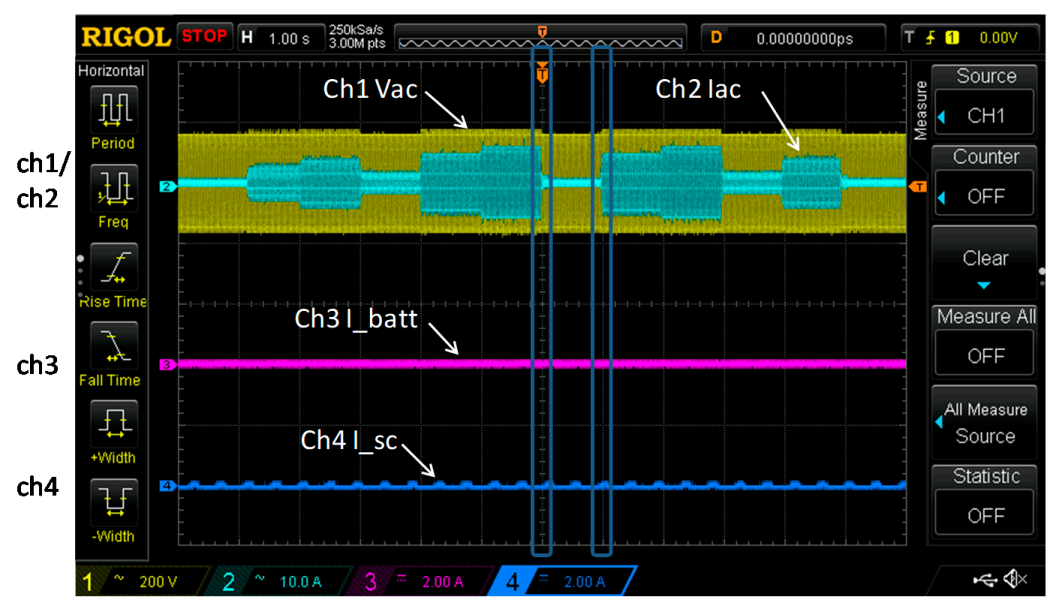

Ch1:200V/div Ch2:10A/div Ch3:2A/div Ch4:2A/div Time:1s/div

Figure 24. Implementation results without RE generation smoothing: Grid AC voltage and current/battery current/SC current.

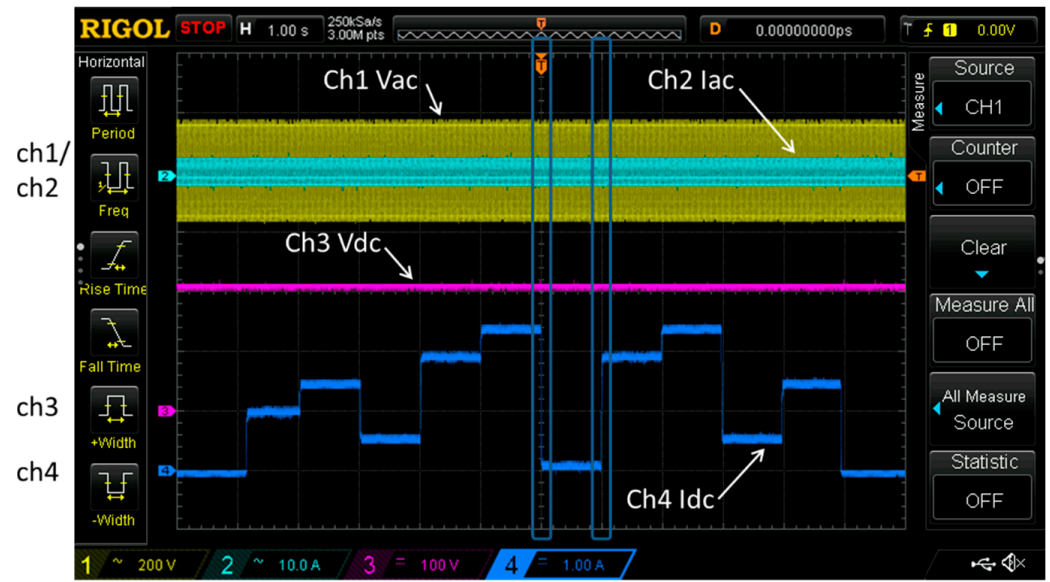

Ch1:200V/div Ch2:10A/div Ch3:100V/div Ch4:1A/div Time:1s/div

Figure 25. Implementation results with RE generation smoothing: Grid AC voltage and current/DC bus voltage/DC bus current.

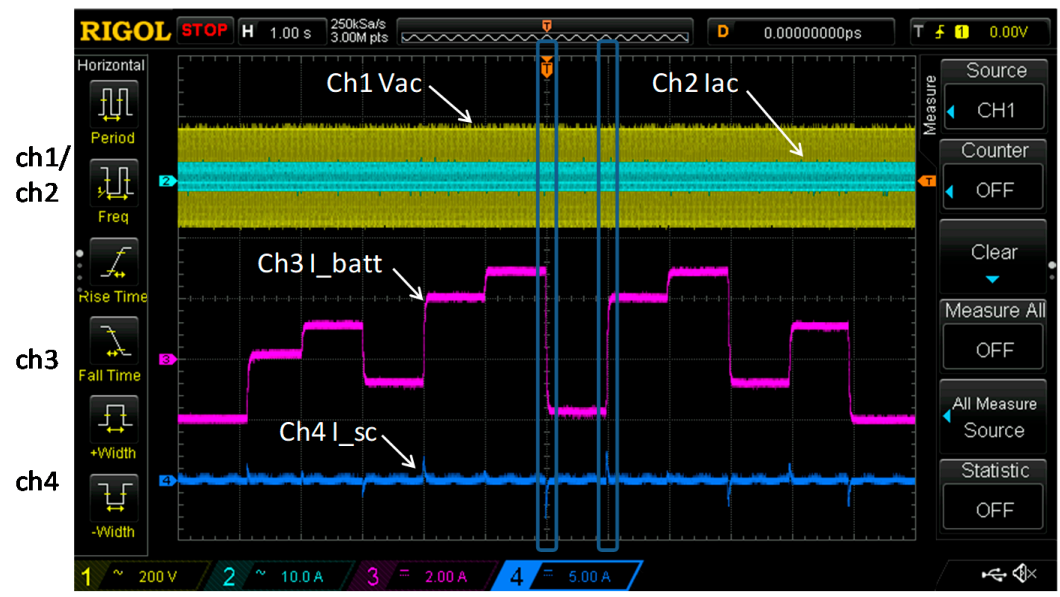

Ch1:200V/div Ch2:10A/div Ch3:2A/div Ch4:5A/div Time:1s/div

Figure 26. Implementation results with RE generation smoothing: Grid AC voltage and current/battery current/SC current. 


\section{Conclusions}

This paper has briefly introduced the importance of ESDs in new power systems and focused on the relevant system characteristics, applications, and power control technologies of CESS. According to the operating conditions of the system, the advanced power control functions and application scenarios of the proposed ICESS have also been introduced. To fill the gap of lacking detailed design examples, especially with hardware verification of CESS systems, a review of the connecting topology and potential application of CESS, system modeling of converters, and systematic design method for controllers of various ESD converters have been presented in this paper. The overall system performance of the proposed SC-battery-based ICESS with the proposed control schemes has been simulated and analyzed with computer software through two typical control cases, peak demand shaving and power generation smoothing, of a grid-connected microgrid. In this paper, the control chip, TMS320F28335, is used as the control kernel to cooperate with the laboratory equipment to carry out the 1-kVA ICESS small-capacity experimental hardware verification. The simulation and implementation results of two typical control cases can prove that the proposed ICESS operation mode and designed digital controllers are feasible and effective. Evaluated from the application aspect, the proposed ICESS is very suitable for small and medium-sized DG systems, especially for optimal real-time control of power flow and energy efficiency. Further investigation on applying intelligent controllers with learning capability and capable of taking into account the states of charge of battery and supercapacitor banks to CESS is a potential future research direction on this topic.

Author Contributions: The corresponding author, C.-T.M. conducted the research work, proposed the ICESS concept and design methods, verified the results, wrote the manuscript draft and polished the final manuscript. C.-L.H. provided administration support from INER. All authors have read and agreed to the published version of the manuscript.

Funding: This research was funded by the Institute of Nuclear Energy Research (INER), Atomic Energy Council, Taiwan, with grant number NL1070422 and NL1090529.

Acknowledgments: The authors would like to thank the Institute of Nuclear Energy Research (INER), Atomic Energy Council, Taiwan, for financially support the energy-related research regarding key technologies and the design of advanced energy storage systems.

Conflicts of Interest: The authors declare no conflict of interest.

\section{References}

1. IPCC. 2013: Summary for Policymakers. In Climate Change 2013: The Physical Science Basis; Cambridge University Press: Cambridge, UK; New York, NY, USA, 2013.

2. International Energy Outlook. 2019. Available online: https:/www.eia.gov/outlooks/ieo/ (accessed on 11 August 2020).

3. Argyrou, M.C.; Christodoulides, P.; Kalogirou, S.A. Energy storage for electricity generation and related processes: Technologies appraisal and grid scale applications. Renew. Sustain. Energy Rev. 2018, 94, 804-821. [CrossRef]

4. Wang, Y.; Wang, L.; Li, M.; Chen, Z. A review of key issues for control and management in battery and ultra-capacitor hybrid energy storage systems. eTransportation 2020, 4, 100064. [CrossRef]

5. Jirdehi, M.A.; Tabar, V.S.; Ghassemzadeh, S.; Tohidi, S. Different aspects of microgrid management: A comprehensive review. J. Energy Storage 2020, 30, 101457. [CrossRef]

6. Zimmermann, T.; Keil, P.; Hofmann, M.; Horsche, M.F.; Pichlmaier, S.; Jossen, A. Review of system topologies for hybrid electrical energy storage systems. J. Energy Storage 2016, 8, 78-90. [CrossRef]

7. Ma, T.; Yang, H.; Lu, L. Development of hybrid battery-supercapacitor energy storage for remote area renewable energy systems. Appl. Energy 2015, 153, 56-62. [CrossRef]

8. Rout, T.; Maharana, M.K.; Chowdhury, A.; Samal, S. A comparative study of stand-alone photo-voltaic system with battery storage system and battery supercapacitor storage system. In Proceedings of the 4th International Conference on Electrical Energy Systems (ICEES), Chennai, India, 7-9 February 2018.

9. Wang, Y.; Wang, W.; Zhao, Y.; Yang, L.; Chen, W. A fuzzy-logic power management strategy based on Markov Random prediction for hybrid energy storage systems. Energies 2016, 9, 25. [CrossRef] 
10. Kuperman, A.; Aharon, I.; Malki, S.; Kara, A. Design of a semiactive battery-ultracapacitor hybrid energy source. IEEE Trans. Power Electron. 2013, 28, 806-815. [CrossRef]

11. Etxeberria, A.; Vechiu, I.; Camblong, H.; Vinassa, J.M. Comparison of three topologies and controls of a hybrid energy storage system for microgrids. Energy Convers. Manag. 2012, 54, 113-121. [CrossRef]

12. Kollimalla, S.K.; Mishra, M.K.; Narasamma, N.L. Design and analysis of novel control strategy for battery and supercapacitor storage system. IEEE Trans. Sustain. Energy 2014, 5, 1137-1144. [CrossRef]

13. Ultra, P.; Battery, C.; Jamshidpour, E. Energy management and control of a stand-alone photovoltaic/ultra capacitor/battery microgrid. In Proceedings of the 2015 IEEE Jordan Conf. Applied Electrical Engineering Computer Technology, The Dead Sea, Jordan, 3-5 November 2015; Volume 2, pp. 1-12.

14. Hajiaghasi, S.; Salemnia, A.; Hamzeh, M. Hybrid energy storage system for microgrids applications: A review. J. Energy Storage 2019, 21, 543-570. [CrossRef]

15. Chen, M.; Cheng, Z.; Liu, Y.; Cheng, Y.; Tian, Z. Multitime-Scale Optimal Dispatch of Railway FTPSS Based on Model Predictive Control. IEEE Trans. Transp. Electrif. 2020, 6, 808-820. [CrossRef]

16. Sinh, S.; Bajpai, P. Power management of hybrid energy storage system in a standalone DC microgrid. J. Energy Storage 2020, 30, 101523. [CrossRef]

17. Chen, X.; Shi, M.; Zhou, J.; Chen, Y.; Zuo, W.; Wen, J.; He, H. Distributed Cooperative Control of Multiple Hybrid Energy Storage Systems in a DC Microgrid Using Consensus Protocol. IEEE Trans. Ind. Electron. 2020, 67, 1968-1979. [CrossRef]

18. Nakka, P.C.; Mishra, M.K. Droop characteristics based damping and inertia emulation of DC link in a hybrid microgrid. IET Renew. Power Gen 2020, 14, 1044-1052. [CrossRef]

19. Nguyen, V.T.; Shim, J.W. Virtual Capacity of Hybrid Energy Storage Systems Using Adaptive State of Charge Range Control for Smoothing Renewable Intermittency. IEEE Access 2020, 8, 126951-126964. [CrossRef]

20. Wang, Y.; Song, F.; Ma, Y.; Zhang, Y.; Yang, J.; Liu, Y.; Zhang, F.; Zhu, J. Research on capacity planning and optimization of regional integrated energy system based on hybrid energy storage system. Appl. Therm. Eng. 2020, 180, 115834. [CrossRef]

21. Kumar, J.; Agarwal, A.; Singh, N. Design, operation and control of a vast DC microgrid for integration of renewable energy sources. Renew. Energy Focus. 2020, 34, 17-36. [CrossRef]

22. Armghan, H.; Yang, M.; Wang, M.Q.; Ali, N.; Armghan, A. Nonlinear integral backstepping based control of a DC microgrid with renewable generation and energy storage systems. Int. J. Electron. Power 2020, 117, 105613. [CrossRef]

23. He, L.; Li, Y.; Guerrero, J.M.; Cao, Y. A Comprehensive Inertial Control Strategy for Hybrid AC/DC Microgrid With Distributed Generations. IEEE Trans. Smart Grid 2020, 11, 1737-1747. [CrossRef]

24. Armghan, H.; Yang, M.; Armghan, A.; Ali, N.; Wang, M.Q.; Ahmad, I. Design of integral terminal sliding mode controller for the hybrid AC/DC microgrids involving renewables and energy storage systems. Int. J. Electron. Power 2020, 119, 105857. [CrossRef]

Publisher's Note: MDPI stays neutral with regard to jurisdictional claims in published maps and institutional affiliations.

(C) 2020 by the authors. Licensee MDPI, Basel, Switzerland. This article is an open access article distributed under the terms and conditions of the Creative Commons Attribution (CC BY) license (http://creativecommons.org/licenses/by/4.0/). 